\title{
Glass Crystal Models: A First Approach to a Hidden Treasure of Teaching and Scientific Heritage
}

\author{
Carolina Peixe ${ }^{1,2, \dagger}$, Conceição Casanova ${ }^{1,3, *, \dagger}$, Joana Lia Ferreira ${ }^{1,3, \dagger}$ and Inês Coutinho ${ }^{1,2,3, *,+}$ \\ 1 Departamento de Conservação e Restauro, Faculdade de Ciências e Tecnologia, \\ Universidade NOVA de Lisboa, Campus de Caparica, 2829-516 Caparica, Portugal \\ 2 Research Unit VICARTE, Vidro e Cerâmica para as Artes, FCT NOVA, Lisboa, Campus de Caparica, \\ 2829-516 Caparica, Portugal \\ 3 LAQV-REQUIMTE, Universidade NOVA de Lisboa, Campus de Caparica, 2829-516 Caparica, Portugal \\ * Correspondence: mccasanova@fct.unl.pt (C.C.); icoutinho@fct.unl.pt (I.C.) \\ $\dagger$ These authors contributed equally to this work.
}

Received: 31 July 2019; Accepted: 26 August 2019; Published: 29 August 2019

check for updates

\begin{abstract}
Glass crystal models arrived in Portugal around the late 19th century, when high schools, universities, and polytechnics were gradually provided with teaching collections to support science education. Therefore, they are an important material evidence of teaching methodologies of mineral and geology science in the 20th century. The Passos Manuel high school in Lisbon, owns a significant collection of scientific heritage, currently on a long-term loan at the National Museum of Natural History and Science and the University of Lisbon, which includes a set of 98 glass crystal models. Besides glass, these models are composed by adhesives, paper, cardboard, textile threads, paper/textile adhesive tapes, and metal nuts and screws. Also, they show several levels of intervention and different conservation states. In this paper, the first results of a multi-analytic approach to chemically characterize these objects' material composition will be presented. Characterization was done based on portable equipment ( $\mathrm{pXRF}$ ), or by collecting small samples further analyzed using optical microscopy and FTIR-ATR techniques. This study allowed for a first distinction between original materials from the old repairs; to develop a more accurate assessment of the conservation condition; and finally, as one of the main aims of this work, to determine preventive conservation measures in order to better preserve these cultural objects.
\end{abstract}

Keywords: glass crystal models; teaching collections; material characterization; preventive conservation; scientific heritage

\section{Introduction}

\subsection{Historic Background: Comprehending the Origins of Glass Crystal Models}

Late in the 16th century, the study of crystals was mostly done through books on minerals and mining industries [1]. In 1546, the first book on mineralogy, De Natura Fossilium by Georgius Agricola (1494-1555), was edited. In this book, the classification of minerals was divided by their physical characteristics, that is, color, weight, transparency, shine, flavor, smell, shape, and texture [1,2]. De Natura Fossilium came to demystify the superpowers of minerals, presenting them for their natural properties and also stressing out the importance of the different geometric forms [1].

Throughout the 16th century, several studies on mineralogy were published, among them De Subtilitate (1550) by the Italian Girolamo Cardano (1501-1576); De Re Metallica (1551) by Christoph Entzelt (1517-1586); and in the year of 1556, Georgius Agricola launched his work, also entitled De Re Metallica, that mainly approached mining techniques, but he also related the minerals by their physical characteristics and mentioned the variety of crystalline forms of the minerals [1]. 
It is worth mentioning the work of Wentzel Jamitzer (1508-1586), a master goldsmith and German jeweller, who published the results of his study, Perspectiva Corporum Regularium, in 1568, which consisted of preparing 140 models with geometric shapes. After that, in 1621, Willebrord Snel (1580-1626) discovered the law of the refraction of light when it crosses a liquid. This would be a discovery of great importance for crystallography, however, it was only revealed through a mention in the book of Vossius, De Lucis Natura et Proprietate (1662) [1]. So, as early as 1665, Robert Hook (1635-1703) published Micrographia, where he described and observed under the microscope countless materials including some crystals. Hook described the regularity of the angles between corresponding faces, regardless of the infinite variety of crystal sizes [1].

Despite the developments of the 16th and 17th centuries, the first known references to crystallographic models linked to mineralogy only appear in the 18th century. After 1735, the Swedish naturalist C. Linneaus (1707-1778) prepared these types of models in wood. However, it was only in the 1780s that crystallographic models were connected to crystallography studies. These were created as a way to give a 3D vision, as until then the models were only seen as flat drawings [3]. In 1772, Romé de L'Isle (1736-1790) published the first edition of the famous Essai de Cristallographie, where crystallography and mineralogy were defined as science. This book included illustrations, which the author called developments, that consisted of foldable surfaces that contained lines enabling a 3D reconstruction of the shape of the crystals [3]. After the success of the first edition, the author then released a second one, more extensive, with 483 illustrations of crystals and minerals from his private collection. With the support of a recorder and two students, 3D terracotta models were created to be sent to their subscribers as a prize [3].

After the development of the goniometer prototype by Carageot in 1780, it became possible to measure interplanar angles close to half a degree, which was viable due to the use of terracotta models instead of natural crystals [3]. After approximately 20 years, terracotta was replaced by wood (Figure 1), since it allowed for softer faces, more defined edges, and a greater rigor in the creation of angles [3]. Since the introduction of these models by Romé L'Isle, the quantity of its production increased, being simultaneously required as models for education and for mineral collections [3].

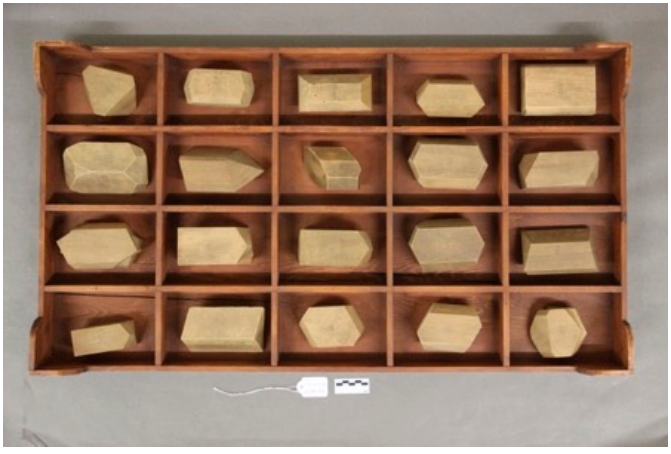

(a)

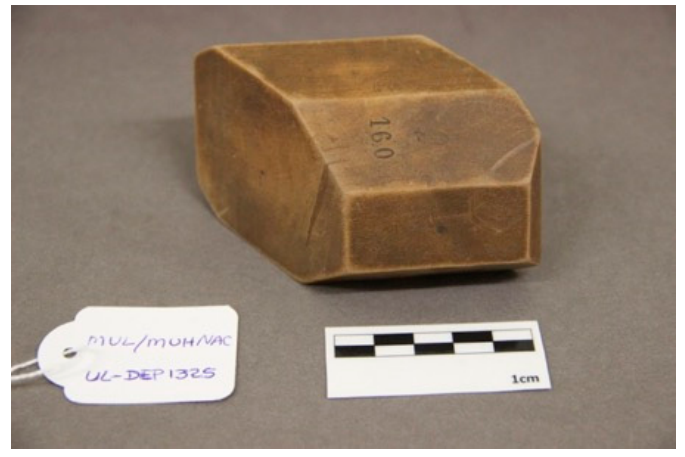

(b)

Figure 1. Crystal models in 3D made of wood. (a) Box with a set of wooden crystal models and (b) wood crystal model from a box set (UL-DEP1325), both from the Passos Manuel high school collection, currently at MUHNAC.

Throughout the 19th century, the importance of these collections in science education at university level, as well as in secondary and primary education, led to the emergence of a global industry with a focus on France, Germany, and England. The creation of the Krantz company at Bonn in 1833, fit the increasing production and requisition of these materials. The company was set by the hand of Adam August Krantz, who started the production of crystallographic models in glass (Figure 2) [4]. The company still runs under the rule of the same family [4]. 


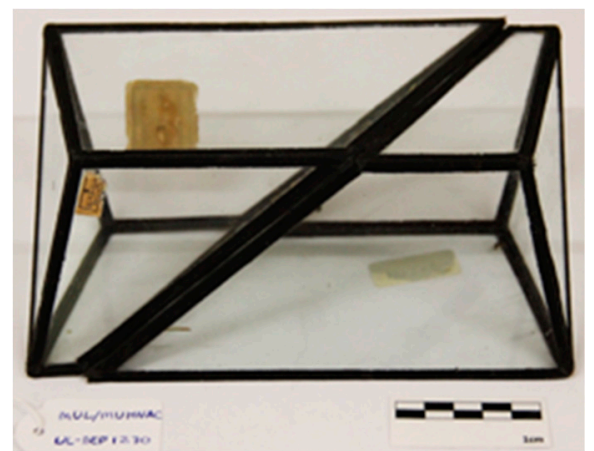

(a)

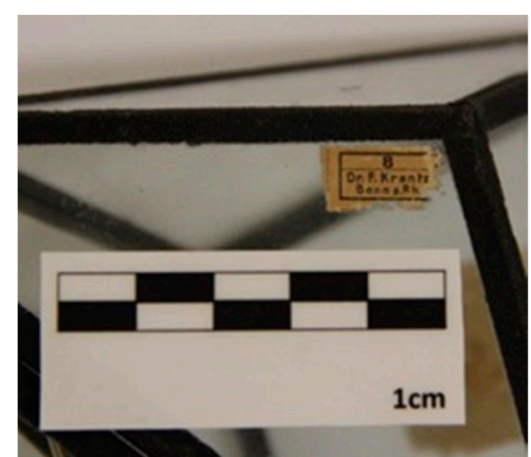

(b)

Figure 2. Glass crystal model (UL-DEP1270) from the Passos Manuel high school collection at MUHNAC (a) model with label from Krantz Company; (b) detail of the label from Krantz company.

\subsection{Passos Manuel High School and the Models under Study}

Glass crystal models collection, the case study treated in this paper, is nowadays part of the natural history teaching collection of an important and centenary Portuguese high school, the Passos Manuel, which was founded following the education law of November 17 of 1836 by the minister Manuel da Silva Passos (1805-1862), also known as Passos Manuel [5]. This law established the high schools' network across the country districts under the national plan for the improvement of secondary education (following the French 'lycée' as a model) [6]. The full study of these collections enables a better comprehension of past teaching methodologies and as well, unveils aims, policies, and practices of science teaching in Portugal during the mid-nineteenth and twentieth centuries. Furthermore, it also contributes to add value to these collections as a historical material evidence of scientific heritage, and ultimately, to the development of good practices for their long-term preservation.

From the perspective of the history of science, the study of this particular set of glass models underlines the relevance of material cultures as primary sources through their interpretation, fostering the knowledge about their use in teaching practices, along with the collection's connection with the education policies on the reorganization of science teaching in Portugal, which, at the time, appears to have been transversal to whole country [6]. Also, the objects' biography promotes the understanding of their significance within a particular school community and their importance in the knowledge transfer process in a certain space and time.

On the other hand, from the perspective of material and conservation science, the full study of glass crystal models will enable researchers and conservators to increase knowledge about manufacturing methods, deterioration processes, and preservation needs. The compositional characterization of their materials will strongly contribute to the development of conservation and restoration methodologies, along with preventive conservation guidelines that will ultimately provide schools, museums, and other institutions with tools to better preserve their glass crystal models. Besides raising the awareness about this important legacy, this last perspective is thus the main aim of this paper besides. In fact, as far as the authors know, this is the first systematic study that focuses on the glass crystal models collection, with the aim of performing an accurate assessment of its conservation condition and determining preventive conservation measures in order to better preserve the models for the present and future generations.

The crystal glass models under study are in storage and long-term deposit at Museu Nacional de História Natural e da Ciência (MUNHAC), but as previously mentioned they belonged to Passos Manuel high school. This school possesses a vast collection of scientific instruments and specimens of natural history (such as chemicals glass containers, fluid, and taxidermized specimen collections, among others), as well as crystallographic models, namely wood models present in large quantities and 98 crystal glass models. The latter are fragile three-dimensional composite items with a certain complexity. They are mainly formed by glass surfaces and large quantities of paper, present in the geometric figures kept inside the glass surfaces, in the paper adhesive tapes to join the glass edges, 
and in several paper labels with manuscript ink, used in different inventories. Some of the glass crystal models also show threads and metal nuts and screws. MUHNAC have the responsibility to preserve and to promote the access to this collection, in general in a fair condition but, until now, these have been little studied. Also, considering some of the visible conservation problems and the need for safe long-term loan and availability of the collection, its further study represents a great challenge. Thus arose the possibility to set a project for the interdisciplinary study of these glass crystal models, under the partnership between MUHNAC, VICARTE (research unit 'Vidro e Cerâmica para as Artes', in English 'Glass and Ceramics for the Arts', NOVA School of Science and Technology (FCT NOVA)) and the Conservation and Restoration Department, FCT NOVA. Preliminary working methodology involved a macro observation and systematization of the entire set by form and/or main materials through visual identification. In Portugal, the provision of high schools with natural history collections to support science teaching was considered a priority for the Portuguese government, namely after Passos Manuel reform. In 1895, the discipline of natural history was integrated into the curriculum of secondary education and despite some criticisms regarding the lack of material, it is known that at that time more than $70 \%$ of high schools had collections of zoological, botanical, geological, and mineralogical specimens [6]. It is believed that the increasing of availability of this type of model happened in the 20th century. This is the case of Passos Manuel high school, from where one can find a large number of crystal wooden models (Figure 1b) and 98 glass crystal models, some of these still with labels from the Krantz company (Figure 2a,b).

In the absence of any reference to a national manufacturer of such models, it is highly probable that most of the glass crystal models would have been imported from abroad. They were then distributed to the country's main high schools when science disciplines were also established in the education curriculum. According to a survey made in historic record sources dated to between 1966 and 1972, many requisitions of crystallographic models of wood and plastic were made. This is probably linked to the fact that the fragility of glass made it easier to request models of other materials [6]. In relation to glass crystal models, these are also found in large numbers in schools, namely high schools, polytechnics, and universities in Portugal, with more found in the main cities [6].

The importance of this study is also related to the experimental designed used, since it operated nondestructively to quasi-destructive and aimed at: (i) Distinguishing the original materials from latter repairs/alterations; (ii) performing an accurate assessment of the conservation conditions and preservation needs of these objects; and, (iii) determining preventive conservation measures, in order to better preserve these cultural and scientific objects. The main results, still from a preliminary approach, will be presented in this paper.

\section{Analytic Study: Materials and Methods}

The preliminary approach to the study of the glass crystal models collection involved macro observation that allowed for the identification of four main typologies (Table 1), from which individual representative case studies were selected for a deeper analytic study. These were then compared with the information collected from the literature, namely the models' manufacturing catalogues and the general information gathered for the state of the art presentation of the historical context $[3,4,7]$.

Table 1. Main typologies of glass crystal models.

\begin{tabular}{ccc}
\hline Typology & Brief Description & Models Quantity \\
\hline A & Glass crystal model with textile lines inside, representing the crystal axes & 63 \\
B & Glass crystal model with interior model made of cardboard, representing the crystal axes & 24 \\
C & Glass crystal model with two rotating parts, showing the ability of the crystal to gain & 8 \\
different forms & Glass crystal models that do not fit any of the characteristics mentioned above, probably & 3 \\
\hline
\end{tabular}


The careful and systematic examination and observation was also essential for the evaluation of the conservation condition of the collection, the definition of the main pathologies and problems observed and to be faced, as well as the selection of the paradigmatic case studies for a deeper analytical study. A comparative scale of three main deterioration grades was established for more precise conservation condition determination: (i) Poor conservation condition, where the glass is broken with missing parts, the interior thread lines or paper model are broken/ripped, and the paper adhesive tapes that join the glass edges are separating from the glass, weak, and failing on the adhesion to the glass; (ii) fair conservation condition, where the glass might be broken in some of the sides but no material is missing, the interior paper models or thread lines are not broken/ripped, and the paper adhesive tapes that join the glass edges might be lifting in some points, but the model integrity is not at risk; (iii) good preservation condition, where all the components seem to be complete and in place.

As mentioned before, 15 models were selected as being representative of the collection under study. The first criteria was to make sure that models from each of the four defined typologies presented in Table 1 were selected, six from A, six from B, one from $C$, and two from D. To have all the typologies was a way to also have access to all the materials that one can find on these models. As part of the choosing criteria, the conservation state of the models was also considered. The models in poor condition were preferred, since it is easier to collect samples and access to the interior materials in models that are less structurally cohesive. The selection contained nine models attributed to the Krantz company, five to altered models, and the only model that is proposed to be an in-house production (UL-DEP1249).

Concerning the selection and collecting of samples, the following materials were sampled: Small samples were collected from the inner paper/cardboard models, from the adhesive tapes (apparently made of paper or textile) that join together the glass faces of the crystal models (both fibers and adhesives were sampled), textile fibers from the interior axes lines, and paper labels (both paper fibers and adhesives were sampled). The sampling was performed by resorting always to areas where the exterior glass was broken, which enabled us to reach the interior paper models and textile axes. To sample the interior paper models and textile axes, the areas that presented damage were the preferred ones (for example, the ripped textile axes were the ones selected for sampling). Also, small samples of the papers and of the tapes were taken from unobtrusive areas of the artefact, along edges or previously damaged areas, and were prepared in identical way as the fibers' threads. Concerning the adhesives that were analyzed by means of FTIR-ATR, the principle of using damaged areas was also applied, using parts where the adhesive was loose and accessible and where the removal would not compromise the integrity of the object.

The first approach to a thorough characterization of the crystal models was made by means of a complementary multi-analytical approach, with the objective of chemical and molecular identification of the different materials that compose these models. The chemical and molecular characterization of the materials was mainly done by portable micro X-rays fluorescence (pXRF) or by collecting small samples to be further analyzed using optical microscopy $(\mathrm{OM})$ and attenuated total reflectance Fourier-transform infrared (FTIR-ATR) spectroscopy.

The different threads and papers fibers found on the crystal models were analyzed by optical microscopy (OM). Different images were obtained with an Axioplan 2ie Zeiss microscope equipped with a transmitted and incident halogen light illuminator (tungsten light source, HAL 100); UV light (mercury light source, HBO 100 illuminator); and a digital Nikon camera DXM1200F, with Nikon ACT-1 application program software, for microphotographs. Samples were analyzed with $10 \times$ ocular lenses and $5 \times / 10 \times / 20 \times / 50 \times$ objective Epiplan lenses (giving total optical magnification of $50 \times, 100 \times$, $200 \times$, and $500 \times$ ). The small thread samples were taken from loose ends. Fibers were observed under the $\mathrm{OM}$ and identification was tried by using their morphological characteristics [8]. The fiber samples were prepared with distilled water and separated from one another with the help of a needle under a magnifying lens and then mounted on the microscope slide for longitudinal view from lowest to higher magnification, under simple polarized light and cross-polarized light [9]. Six samples of fibers were analyzed from a total of five models (type A, Table 1). The papers/textiles of the tapes were 
identified under the OM [10]. In total, 30 samples of fibers were analyzed, from a total of 15 models, on six different colored tapes.

Microchemical analysis by spot test was performed to very small samples of the inner paper/cardboard models (type B, Table 1) and to micro-samples of the paper labels that were present in all models. The phloroglucinol test was applied for lignin detection, using $1 \mathrm{~g}$ of phloroglucinol dissolved in a mixture of $50 \mathrm{~mL}$ methanol, $50 \mathrm{~mL}$ concentrated $\mathrm{HCL}$, and $50 \mathrm{~mL}$ distilled water, taking into consideration TAPPI norms (T401 norm) [11]. The aluminon test was applied to check the presence of alum salts and a solution of $0.1 \mathrm{~g}$ aluminon in 1 liter of distilled water was prepared [12] (p. 12). The micro-samples were placed on a glass rod and a small drop of each solution was placed on different fiber samples, where the color change was checked with the help of a stereo binocular microscope. In the inner paper/cardboard models samples, the Raspail test was also tried for alum rosin detection, again, having in mind TAPPI recommendations (T408 norm) [13]. First, a drop of saturated sugar solution (about $35 \mathrm{~g}$ sucrose $/ 20 \mathrm{~mL}$ water) was applied to the sample placed on the glass rod, allowed to soak for around three minutes, and the excess sugar solution removed with filter paper. It was followed by the application of one drop of sulfuric acid $\left(96.6 \% \mathrm{H}_{2} \mathrm{SO}_{4}\right)$ on the sample and it was observed with the help of low-power magnification. The reaction should be immediate, and the color change may reveal the presence of alum rosin sizing [12] (p. 13).

Portable X-ray fluorescence spectroscopy (pXRF) was performed in situ, using Bruker S1 Titan Model 600, directly on the glass of the 15 models to determine the type of glass used to build the models. The spectra were acquired under the following conditions: The excitation source is a Rh target X-ray tube of $4 \mathrm{~W}$, with maximum voltage of $50 \mathrm{kV}$ and $100 \mu \mathrm{A}$, elemental range between $\mathrm{Mg}$ and $\mathrm{U}$, and acquired with the integrated acquisition mode calibration GeoExploration, which operates at a 3-phase reading ( $90 \mathrm{~s}$ totally): Phase 1 at $30 \mathrm{kV}, 26 \mu \mathrm{A}$; phase 2 at $50 \mathrm{kV}, 26 \mu \mathrm{A}$; phase 3 at $15 \mathrm{kV}, 26 \mu \mathrm{A}$ (30 s each). Quantitative results were obtained with the automatic quantification proprietary software, Bruker Elemental S1. The elements, initially not presented in oxides, were then converted through oxide factors. To validate the obtained results, the glass standards from the Corning Museum of Glass, CMoG B and CMoG D, were analyzed under the same conditions [14] (p. 544).

Samples of adhesives on tapes and on the glass surface were analyzed by infrared spectroscopy in attenuated total reflectance mode (ATR-FTIR). The spectra were acquired using an Agilent Handheld 4300 FTIR Spectrometer with a DTGS detector, with controlled temperature, and a diamond ATR sample interface; the analyses were performed at the sample surface. All spectra were obtained with a resolution of $8 \mathrm{~cm}^{-1}$ and 32 scans. Twenty adhesive samples were analyzed.

\section{Main Results: Presentation and Discussion}

\subsection{Crystal Models Collection-Macro Observation}

During the preliminary observation of the collection of crystal glass models, four main typologies were recognized (defined in Table 1), related to shape and main materials used. However, several other variations were observed. The paper adhesive tapes that join the glass are not the same for all the models. These came in different colors (black, blue, red, light yellow), different widths, and different textures (some look like a textile and others almost like a plastic material). The paper models inside the glass model can be all of the same color (white paper color) or can have two colors (alternated color sides: One of white paper color and the other of black glazed paper). The thread lines inside the glass models can have different colors, ranging between red, yellow, green, and orange. From the 98 models it was possible to identify one model with a cleavage interior plan on glass (Figure 3a).

For 13 of the models, the different features identified (either different colored paper adhesive tapes or the presence of plaster) can probably be related with latter interventions made overtime due to heavy usage of the objects. Also, it was noticed that four of the 98 models still reveal labels from the Krantz manufacturer. 


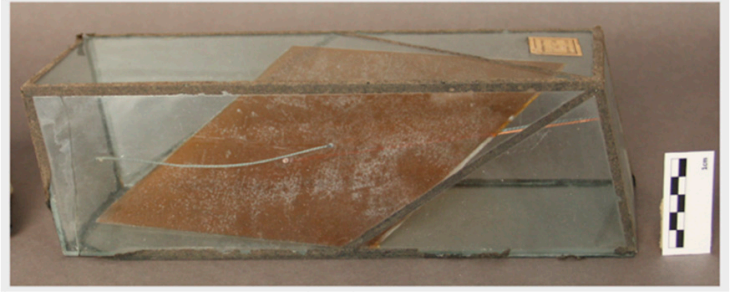

(a)

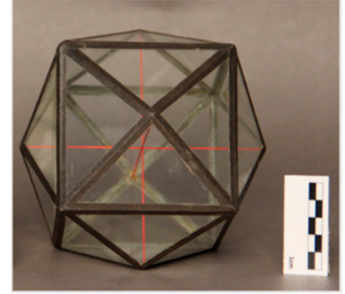

(c)

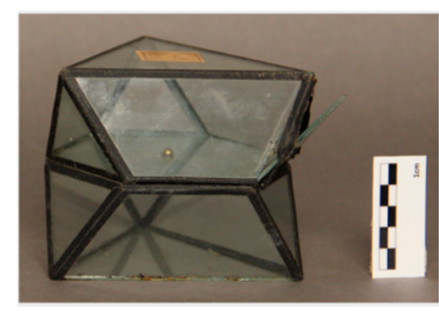

(b)

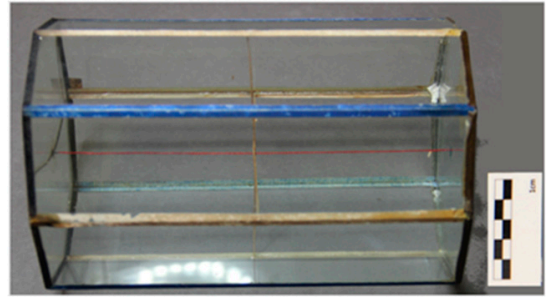

(d)

Figure 3. Krantz company glass crystal models from different generations: (a) Glass crystal model (UL-DEP1321) with inner glass cleavage plan; (b) glass crystal model (UL-DEP1309) with metal nuts for rotation; (c) glass crystal model (UL-DEP1240) with inner textile red lines; (d) glass crystal model (UL-DEP1280) with inner textile red and yellow lines; and blue, red, and black adhesive tapes.

Combining and analyzing the different characteristics mentioned above and comparing it with some catalogues from the Krantz company [7], it was possible to suggest a provenance for different kinds of models within the collection (Table 2).

Table 2. Proposal of provenance for the 98 models from Passos Manuel high school.

\begin{tabular}{ccc}
\hline Model Reference & Provenience & Models Number \\
\hline I & Possibly Krantz Company Models & 85 \\
II & Altered Models & 12 \\
III & Possibly in-house Manufactured Model & 1 \\
\hline
\end{tabular}

From the total 98 models, 85 are possibly from Krantz company, where early models reveal only black paper/textile adhesive tapes (Figure 3a) and later models have colored tapes (red and blue) (Figure 3b), and where the inner thread lines also changed from one color (Figure 3c) to several colors (Figure 3d) such as red, green, yellow, and orange. So, among these 85 models it is possible to notice the evolution of these characteristics and divide them into four distinct types that could represent four generations of glass crystal models made by the Krantz Company.

For the remaining 13 models of the Passos Manuel high school collection, it is not possible to recognize any characteristics from the Krantz models. However, as said before, most of these models appear to have been heavily altered.

As mentioned in the introduction, glass crystal models have a complex structure and the first methodological approach was also associated with the diagnosis of pathologies to estimate, through visual observation, the conservation condition of the collection comprising the 98 models. It is estimated that $23 \%$ of the models are in a poor conservation condition, mainly due to missing parts and lack of adhesion between materials. These models need an urgent intervention in order to avoid the loss of any important information.

Following these, $49 \%$ of the models are in a fair conservation condition, where no material is missing, and the model integrity is not at risk. These models might need some intervention but not at an urgent level.

Finally, 28\% are in a good preservation condition, since all the components are in place and the models seem to be complete. These models do not need any remedial conservation. However, 
for an informed conservation decision and to implement correct preservation measures for the different parts composing the glass crystal models, further characterization of the materials is required.

\subsection{Characterization of the Glass}

The glass was analyzed by means of XRF, using a portable equipment in order to determine the glass chemical composition, which is shown in Table 3. By determining the glass compositional type, one can propose preventive conservation measures in a more informed way. Three points were analyzed for each model and the presented results are the average of those three measurements, together with the respective standard deviation. Only the major elements are presented and the data are normalized to $100 \%$.

Table 3. Chemical composition of the glass from 15 crystal models, determined by pXRF, in weight percent of oxides.

\begin{tabular}{|c|c|c|c|c|c|}
\hline Model Accession No. & $\mathrm{Al}_{2} \mathrm{O}_{3}$ & $\mathrm{SiO}_{2}$ & $\mathrm{~K}_{2} \mathrm{O}$ & $\mathrm{CaO}$ & $\mathrm{Fe}_{2} \mathrm{O}_{3}$ \\
\hline UL-DEP1234 & $1.4 \pm 0.3$ & $83.5 \pm 0.7$ & $0.69 \pm 0.02$ & $14.17 \pm 0.05$ & $0.25 \pm 0.01$ \\
\hline UL-DEP1240 & $0.6 \pm 0.2$ & $89.5 \pm 0.7$ & $0.51 \pm 0.02$ & $9.27 \pm 0.04$ & $0.12 \pm 0.01$ \\
\hline UL-DEP1244 & $1.5 \pm 0.2$ & $85.4 \pm 0.7$ & $0.74 \pm 0.02$ & $12.15 \pm 0.04$ & $0.25 \pm 0.01$ \\
\hline UL-DEP1246 & $0.8 \pm 0.2$ & $90.9 \pm 0.7$ & $0.52 \pm 0.02$ & $7.53 \pm 0.03$ & $0.17 \pm 0.01$ \\
\hline UL-DEP1249 & $1.5 \pm 0.3$ & $83.8 \pm 0.8$ & $0.68 \pm 0.02$ & $13.78 \pm 0.05$ & $0.24 \pm 0.01$ \\
\hline UL-DEP1252 & $0.3 \pm 0.2$ & $82.1 \pm 0.7$ & $0.05 \pm 0.01$ & $17.30 \pm 0.05$ & $0.21 \pm 0.01$ \\
\hline UL-DEP1268 & $1.6 \pm 0.3$ & $84.3 \pm 0.7$ & $0.72 \pm 0.02$ & $13.06 \pm 0.05$ & $0.29 \pm 0.01$ \\
\hline UL-DEP1269 & $2.5 \pm 0.3$ & $81.4 \pm 0.7$ & $1.36 \pm 0.02$ & $14.49 \pm 0.05$ & $0.16 \pm 0.01$ \\
\hline UL-DEP1287 & $0.5 \pm 0.2$ & $83.6 \pm 0.8$ & $0.16 \pm 0.01$ & $15.48 \pm 0.05$ & $0.27 \pm 0.01$ \\
\hline UL-DEP1293 & $1.6 \pm 0.2$ & $84.4 \pm 0.7$ & $0.71 \pm 0.01$ & $13.01 \pm 0.05$ & $0.32 \pm 0.01$ \\
\hline UL-DEP1308 & $0.5 \pm 0.2$ & $83.4 \pm 0.7$ & $0.20 \pm 0.01$ & $15.67 \pm 0.05$ & $0.26 \pm 0.01$ \\
\hline UL-DEP1309 & $0.5 \pm 0.2$ & $85.1 \pm 0.7$ & $0.29 \pm 0.01$ & $13.87 \pm 0.05$ & $0.29 \pm 0.01$ \\
\hline UL-DEP1312 & $1.3 \pm 0.9$ & $84.2 \pm 0.7$ & $0.61 \pm 0.02$ & $13.63 \pm 0.05$ & $0.18 \pm 0.01$ \\
\hline UL-DEP1316 & $2.7 \pm 0.3$ & $84.2 \pm 0.7$ & $1.14 \pm 0.02$ & $11.55 \pm 0.05$ & $0.37 \pm 0.01$ \\
\hline UL-DEP1321 & $1.2 \pm 0.2$ & $81.4 \pm 0.7$ & $0.31 \pm 0.01$ & $16.84 \pm 0.05$ & $0.24 \pm 0.01$ \\
\hline CMoG B & $5.2 \pm 0.4$ & $82.7 \pm 0.7$ & $1.15 \pm 0.02$ & $10.48 \pm 0.04$ & $0.43 \pm 0.01$ \\
\hline CMoG B (certified) ${ }^{1}$ & 5.7 & 81.4 & 1.31 & 11.18 & 0.44 \\
\hline CMoG D & $6.2 \pm 0.4$ & $69.0 \pm 0.7$ & $11.37 \pm 0.06$ & $12.96 \pm 0.05$ & $0.45 \pm 0.01$ \\
\hline CMoG D (certified) ${ }^{1}$ & 6.1 & 63.5 & 12.93 & 16.93 & 0.59 \\
\hline CMoG B (certified) ${ }^{2}$ & 4.4 & 62.3 & 1.00 & 8.56 & 0.34 \\
\hline CMoG D (certified) ${ }^{2}$ & 5.3 & 55.5 & 11.30 & 14.80 & 0.52 \\
\hline
\end{tabular}

${ }^{1}$ Certified values taken from: R. Brill, Chemical Analyses of Early Glasses, Vol. II, The Corning Museum of Glass, Corning (1999), p. 544. The certified values were normalized to $100 \%$ using only the oxides present in this table.

${ }^{2}$ Certifies values taken from the same reference without being submitted to any mathematical operation.

Analyzing Figure 4, where the contents of calcium oxide and potassium oxide are related and compared with the glass standards CMoG B and CMoG D, it is proposed that the glasses used to build the crystal models are of a soda rich type or soda-lime silica glasses, since these are located in the same area of the chart that the CMoG B standard (sodium rich or soda-lime silica standard) is located. The technique used to determine the glass chemical composition does not allow for the determination of the sodium oxide content, that being a light element usually needs an in vacuum set to be determined. The content of potassium oxide is in its majority below $1 \mathrm{wt} \%$, which prevents the glass from being considered of a potassium rich composition or a mixed alkali composition [15]. Moreover, the contents of lead are all below $0.1 \mathrm{wt} \%$, preventing the glass from being of a lead-rich type (lead contents above $25 \mathrm{wt} \%$ ), supporting the proposed glass type. 


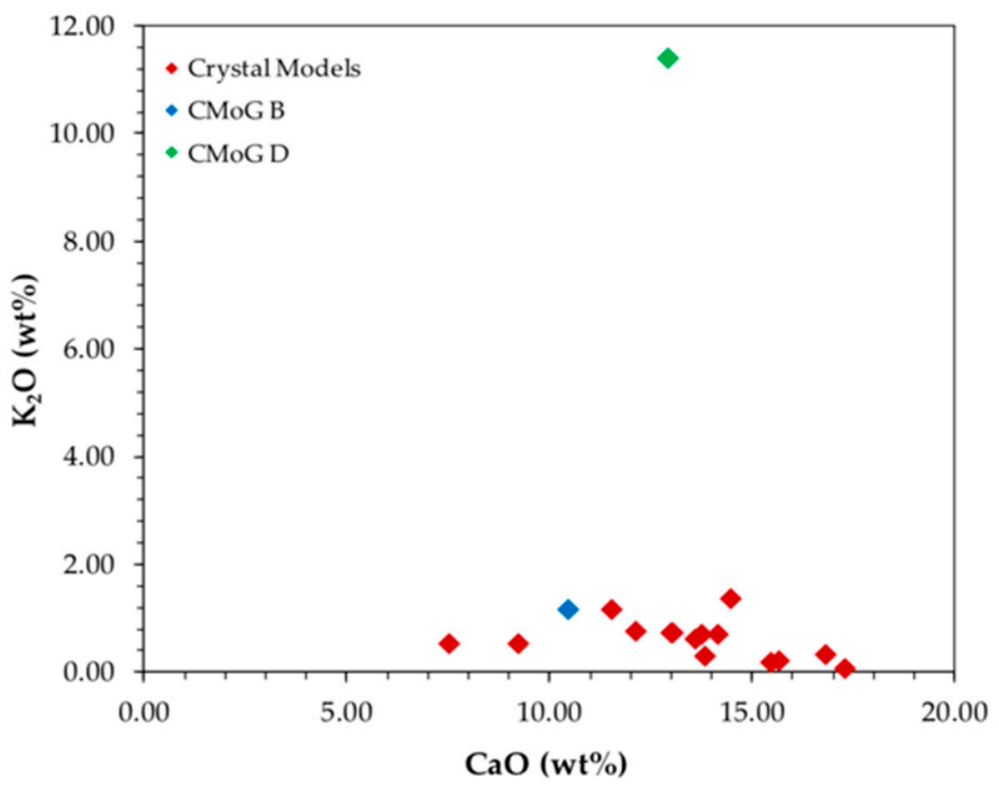

Figure 4. Binary plot of calcium oxide vs. potassium oxide, in weight percent of oxides and measured by pXRF.

\subsection{Characterization of Inner Paper/Cardboard Models and the Thread Lines}

Regarding the paper/cardboards microchemical testing (Table 4), the phloroglucinol spot test was negative except in one case (UL-DEP1249). This means that for one model only, the presence of lignin was found. The aluminon test for alum salts detection and Raspail test for alum rosin were both positive for all cardboard models. So, one can conclude that the model UL-DEP1249, which corresponds to the proposed in-house manufactured model, used very poor materials compared with the other analyzed models. The other models used lignin-free cardboards, although revealing also an acid source, due to the presence of rosin as sizing material.

Table 4. Microchemical tests on models with cardboard interior models.

\begin{tabular}{cccc}
\hline Model Accession No. & Phloroglucionol & Aluminon & Raspail Test \\
\hline UL-DEP1249 & Positive & Positive & Positive \\
UL-DEP1252 & Negative & Positive & Positive \\
UL-DEP1287 & Negative & Positive & Positive \\
UL-DEP1308 & Negative & Positive & Positive \\
\hline
\end{tabular}

Through the observation of the inner line fibers (representing internal crystal axes) it is possible to notice that these are not a single type of fiber but a mixture of fibers. The observation under the OM and the comparison of the images with the database of Conservation and Art Materials Encyclopedia (CAMEO) and the literature $[9,11]$, allows one to suggest the presence of cotton, a flat fiber with ribbon-like appearance revealing twisted areas, thick walls, and small lumen under the microscope (Figure 5a); wild and cultivated silk with a smooth appearance and lustrous filaments (Figure 5b) and even traces of flax or hemp with the presence of lines going across the fiber; and forming cross hatching and knots, plus a narrow lumen (Figure $5 \mathrm{c}$ ).

\subsection{Paper Labels}

Most of the glass crystal models studied presented three labels: The label from Liceu Passos Manuel (Figure 6a), which corresponds with a list of the names from the different crystal representations; smaller labels (Figure 6b), for which correspondence is still undetermined; and labels from their tumble (Figure 6c), a number attributed to each artefact of the collection when entered into the museum. 
As mentioned before, apart from these three labels, there are labels from the Krantz company (Figure 6d) present in four different models, and a few other different types of labels (Figure 6e), such as labels with names or numbers, with no matching correspondence determined so far.

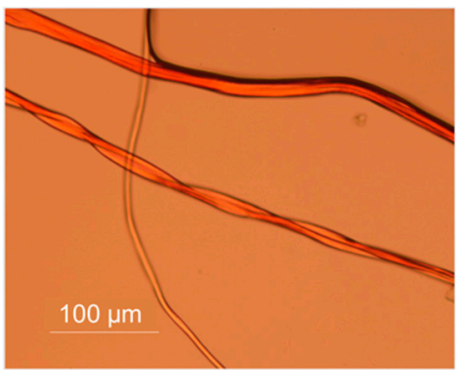

(a)

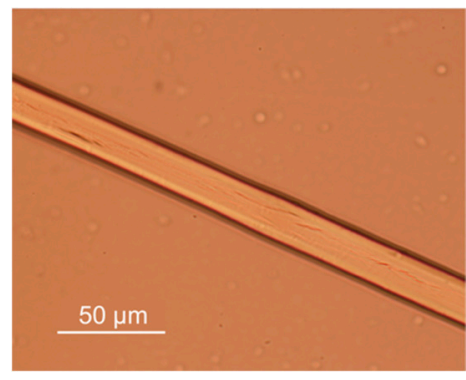

(b)

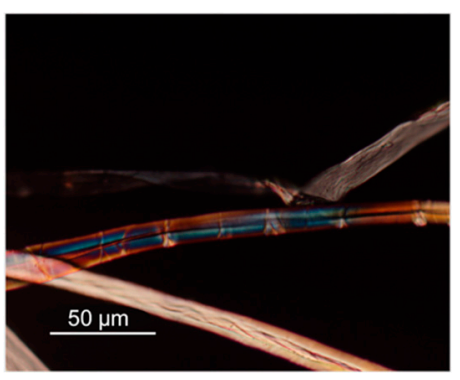

(c)

Figure 5. Fibers under optical microscope: (a) Red inner textile line from UL-DEP1316 model (cotton); (b) beige inner textile line from UL-DEP1312 model (silk); (c) beige inner textile line from UL-DEP1268 model (flax or hemp).

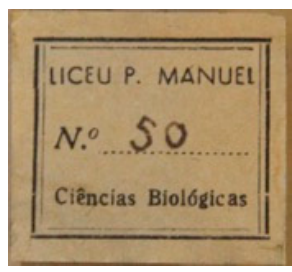

(a)

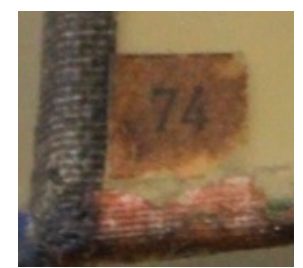

(b)

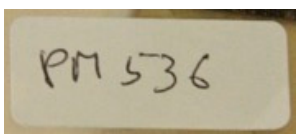

(c)

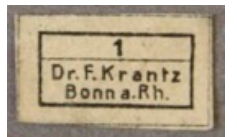

(d)

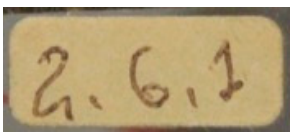

(e)

Figure 6. Labels present in the glass crystal models: (a) Liceu P. Manuel; (b) smaller labels with no given correspondence; (c) tumble number; (d) Krantz company; (e) other labels.

Over time, these kinds of labels become a historic part of the objects, with irreplaceable information, therefore their preservation is an important concern for the intervention of the entire object [16]. For that reason, it is important to observe the different labels and understand their historic and cultural significance, namely trying to determine which ones have this meaning and which have not, as well as to characterize their composition stability. From the labels described in the previous paragraph, the only one that was not considered historic was the tumble label, since these were attached to the models in a chronological line that does not yet correspond to an historical moment.

At that stage, the microchemical tests of phloroglucinol and aluminon were performed on all the labels deemed as historic and the results are presented in Tables 5 and 6, respectively.

Table 5. Phloroglucinol microchemical tests on different paper labels.

\begin{tabular}{ccccc}
\hline Model Accession No. & Liceu P. Manuel & Smaller Labels & Krantz & Other Labels \\
\hline UL-DEP1240 & - & - & - & Negative \\
UL-DEP1249 & - & - & - & Positive \\
UL-DEP1252 & Negative & Positive & - & - \\
UL-DEP1287 & - & - & - & Negative \\
UL-DEP1293 & Negative & Positive & - & - \\
UL-DEP1308 & Negative & Positive & - & - \\
UL-DEP1309 & - & - & Negative & - \\
UL-DEP1321 & Negative & - & - & - \\
\hline
\end{tabular}

Results were consistent for each type of label, apart from the category 'other labels', which revealed some inconsistent results. Analyzing each type of label separately, the paper revealing the best quality was the one from the Krantz company, due to the absence of lignin (phloroglucinol test) and alumen (aluminon test). The Liceu P. Manuel labels also presented good quality, based on the absence of lignin 
and despite the presence of alum salts; the small labels represented a concern, since the presence of lignin (phloroglucinol test was positive) will cause acidic hydrolysis of the paper and its dislocation and chemical and physical alteration, already visible by its color appearance. These labels did not reveal alum salts, but the presence of lignin indicates mechanical wood pulp production and therefore, acid hydrolysis deterioration. Finally, the 'other labels' did not present consistent results, alternating between good and bad quality.

Table 6. Aluminon microchemical tests on different paper labels.

\begin{tabular}{ccccc}
\hline Model Accession No. & Liceu P. Manuel & Smaller Labels & Krantz & Other Labels \\
\hline UL-DEP1240 & - & - & - & Negative \\
UL-DEP1249 & - & - & - & Positive \\
UL-DEP1252 & Positive & Negative & - & - \\
UL-DEP1287 & - & - & - & Positive \\
UL-DEP1293 & Positive & Negative & - & - \\
UL-DEP1308 & Positive & Negative & - & - \\
UL-DEP1309 & - & - & Negative & - \\
UL-DEP1321 & Positive & - & - & - \\
\hline
\end{tabular}

\subsection{Adhesives and Constructive Tapes}

Observing the fibers from the adhesive tapes under the OM and comparing it with the mentioned literature, it is possible to identify different types of fibers. A mixture of cotton and other fibers could be identified through the presence of its characteristic, such as a ribbon-like appearance revealing twisted areas for cotton (Figure 7a), lines going across the fiber and forming cross hatching and knots for flax or hemp (Figure $7 \mathrm{~b}$ ), and longitudinal lines for jute fibers (Figure 7c). In the samples observed, textile cotton fibers seem dominant. The only tape where it was possible to identify the presence of a softwood fiber showing sequenced pits and other species' features, such as ray parenchyma (Figure 7d) was in the black tape of the model UL-DEP1234, being that this was the item that was heavily repaired, so this came probably from a latter intervention.

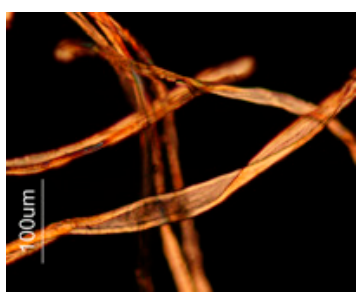

(a)

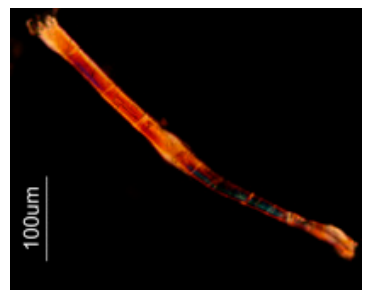

(b)

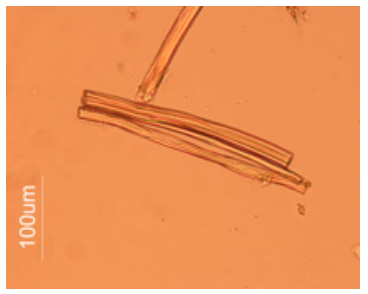

(c)

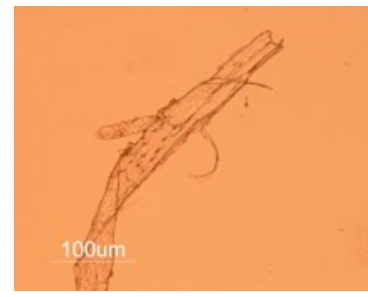

(d)

Figure 7. Fibers under the optical microscope: (a) Cotton sample from UL-DEP187 model; (b) flax or hemp sample from UL-DEP1312 model; (c) jute sample from UL-DEP1268 model; (d) softwood sample from UL-DEP1234.

The adhesives and constructive tapes were also analyzed by means of ATR-FTIR, resorting to the use of a portable equipment to make the molecular characterization. From the 20 samples of adhesives analyzed by means of ATR-FTIR, seven were identified as protein based glue, four as protein glue and cellulose, two as cellulose, and in five of the samples other components were identified. These last five samples contained protein, cellulose, and materials that were identified as gypsum, kaolin, Arabic gum, and shellac. In two other samples the presence of poly(vinyl acetate) (PVAc) was also identified. The presence of these last mentioned materials is probably the result of some changes made by the school professors, or other professionals, during the period of use of the models, with the objective of making the necessary repairs for the models to become useful and usable again.

In Figure 8, spectra from three samples collected from different parts of the models UL-DEP1308 and UL-DEP1309 are presented. Spectrum (a) was collected from model UL-DEP-1308, from an edge of 
glass without paper adhesive tape and spectrum (b), which came from the same model, was removed from a glass face near a paper adhesive tape. Spectrum (c) was collected from model UL-DEP1309, from a glass edge that had no contact with paper adhesive tape. Two types of materials were identified: protein (b), cellulose (c), and the mixture of the two (a). Protein spectra are typically recognized by the presence of the carbonyl group belonging to the amide I (here at $1630 \mathrm{~cm}^{-1}$ ) and of amide II $\left(1536 \mathrm{~cm}^{-1}\right)$. These, along with a third one, usually named by amide III (at $\left.1454 \mathrm{~cm}^{-1}\right)$, form the characteristic stair-step pattern. Being coupled with the N-H stretching band (centered at ca $3275 \mathrm{~cm}^{-1}$ ), it is possible to confirm the presence of the amide, and so, the protein [17]. Therefore, it is possible to infer that one of the present adhesives might be some type of protein glue, despite being impossible to further determine which adhesive it is.

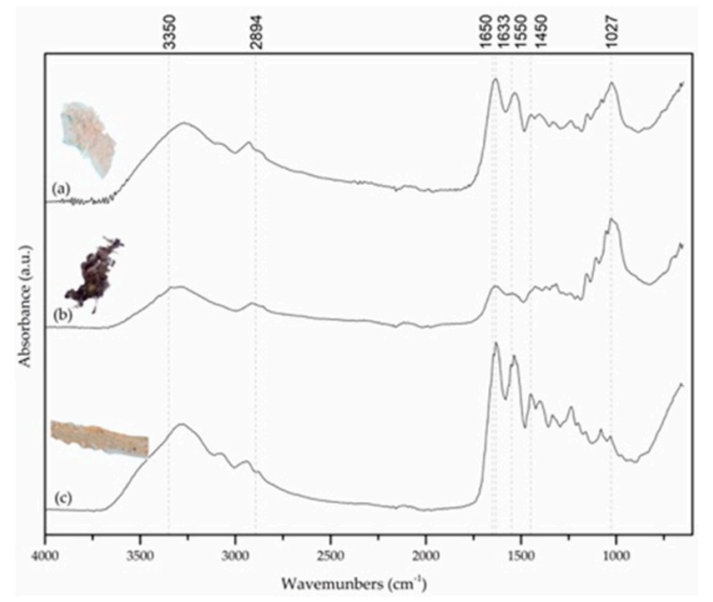

Figure 8. ATR-FTIR spectra of (a) protein and cellulose from UL-DEP1308 model; (b) cellulose from UL-DEP1309 model; and (c) protein sample from UL-DEP1309 models.

Cellulose spectra can be recognized by two regions of absorbing bands, first between $3660-2800 \mathrm{~cm}^{-1}$ and second at $1650-400 \mathrm{~cm}^{-1}$. The first region is characterized by the stretching vibration of the hydroxyl group (centered at $3290 \mathrm{~cm}^{-1}$ ) and the band attributed to $\mathrm{CH}$ stretching vibration of the hydrocarbon groups in polysaccharides (ca $2915 \mathrm{~cm}^{-1}$ ). The second region comprises the vibration band of water (ca $1637 \mathrm{~cm}^{-1}$ ) and bending vibrations of $\mathrm{CH}$ and $\mathrm{COH}$ (at ca 1428, 1367, $\left.1334 \mathrm{~cm}^{-1}\right)$, and the COC stretching vibrations $\left(1027\right.$ and $\left.896 \mathrm{~cm}^{-1}\right)$ [18]. The presence of cellulose is probably due to contamination of the sample, being that this sample came from an adhesive tape. The presence of softwood, which can be seen on the samples of the model UL-DEP1308, spectrum (a) probably justifies the two components, protein and cellulose.

In the spectrum presented in Figure 9, the presence of PVAc was identified among the adhesives used in the glass crystal models of the collection. This sample was collected between the paper adhesive tape and the glass edges. Among the 15 models selected as being representative of the collection of 98 models, this is one of two models that have PVAc, with the second one colored in black, perhaps to match the color of the tape where it was applied. This type of adhesive is identified by the presence of the strong $\mathrm{C}=\mathrm{O}\left(\right.$ at $\left.1729 \mathrm{~cm}^{-1}\right)$ and $\mathrm{C}-\mathrm{O}-\mathrm{C}\left(1224 \mathrm{~cm}^{-1}\right)$ stretching vibration bands related with the acetate ester, along with two less intense peaks of $\mathrm{CH}_{3}$ asymmetric and symmetric bending bands (at $1433 \mathrm{~cm}^{-1}$ and $1370 \mathrm{~cm}^{-1}$, respectively). Additionally, there is also an antisymmetric stretching vibration of $\mathrm{CH}_{3}\left(2973 \mathrm{~cm}^{-1}\right)$ [18].

In some models it was possible to identify other materials (Figure 10) such as gypsum, Arabic gum, shellac, and kaolin, and these samples were collected from around the smaller label (Arabic gum), from an adhesive tape (kaolin) where Arabic gum was also present, and from edges of glass without adhesive tape (gypsum and shellac). 


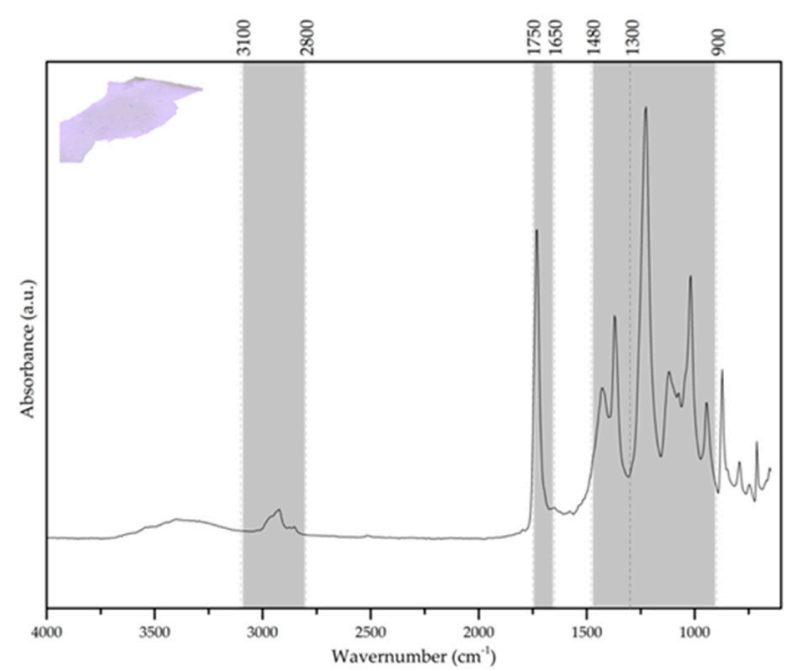

Figure 9. ATR-FTIR spectrum of poly (vinyl acetate) (PVAc) from sample of UL-DEP1287 model.

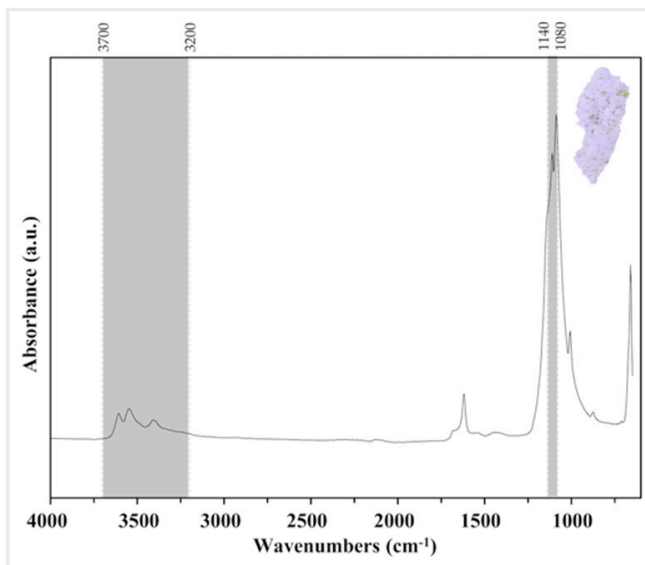

(a)

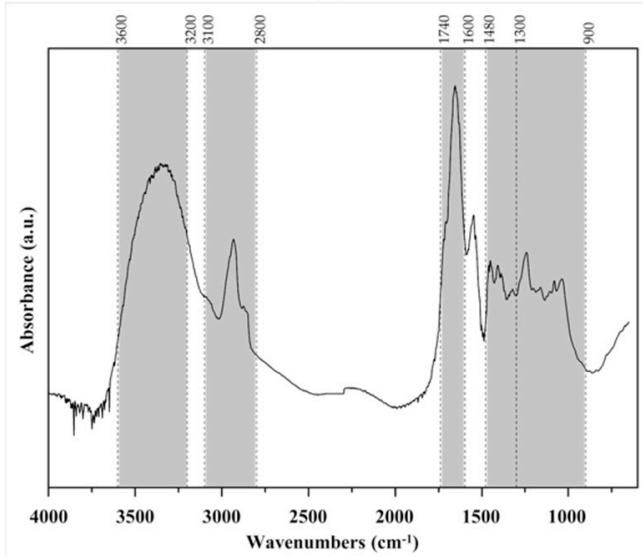

(c)

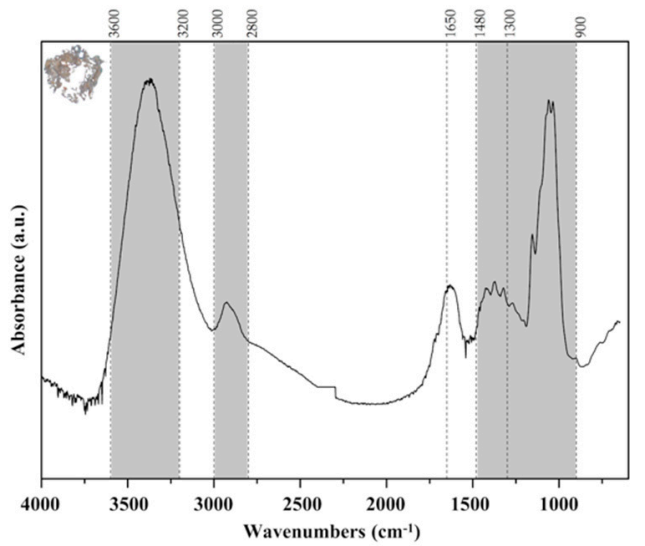

(b)

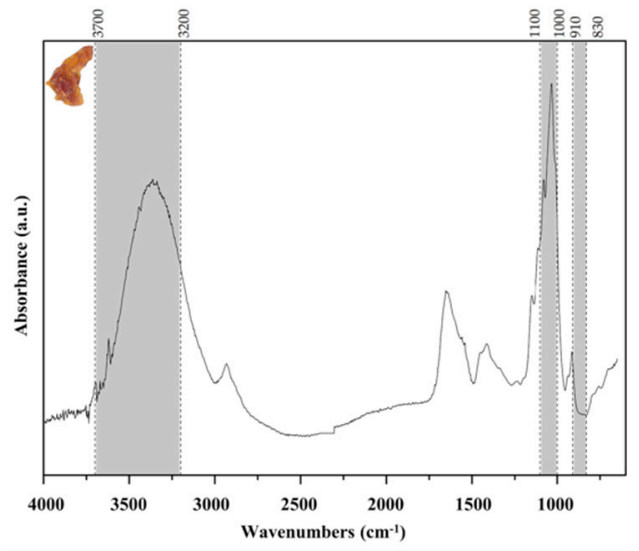

(d)

Figure 10. ATR-FTIR spectrum of (a) gypsum from sample of UL-DEP1316 model; (b) Arabic gum from sample of UL-DEP1308; (c) shellac from sample of UL-DEP1269; (d) kaolin from sample of UL-DEP1316.

Gypsum (Figure 10a) is generally identified by having an asymmetric $\mathrm{SO}_{4}{ }^{3-}$ stretching band between ca $1140-1080 \mathrm{~cm}^{-1}$ and an antisymmetric and symmetric $\mathrm{OH}$ stretching band [17]. Arabic gum (Figure 10b) is identified by the $\mathrm{OH}$ stretching band between ca $3600-3200 \mathrm{~cm}^{-1}, \mathrm{CH}$ stretching band between ca 3000-2800 $\mathrm{cm}^{-1}, \mathrm{OH}$ bending band at ca $1650 \mathrm{~cm}^{-1}, \mathrm{CH}$ bending band between ca $1480-1300 \mathrm{~cm}^{-1}$, and finally CO stretching bands between 1300-900 $\mathrm{cm}^{-1}$ [17]. Shellac (Figure 10c) 
presents the typical bands at five different regions, the $\mathrm{OH}$ stretching band at ca $3600-3200 \mathrm{~cm}^{-1}, \mathrm{CH}$ stretching bands at $3100-2800 \mathrm{~cm}^{-1}, \mathrm{C}=\mathrm{O}$ stretching band at ca $1740-1640 \mathrm{~cm}^{-1}$, the $\mathrm{CH}$ bending bands at ca 1480-1300 $\mathrm{cm}^{-1}$, and the CO stretching bands at ca $1300-900 \mathrm{~cm}^{-1}$ [17]. Finally, kaolin (Figure 10d) is identified by the $\mathrm{OH}$ stretching band at ca $3700-3200 \mathrm{~cm}^{-1}$, the asymmetric $\mathrm{Si}-\mathrm{O}-\mathrm{Si}$ stretching band at ca $1100-1000 \mathrm{~cm}^{-1}$, and $\mathrm{SiO}$ stretching at ca $910-830 \mathrm{~cm}^{-1}$ [17].

The presence of the different materials mentioned above, gypsum, kaolin, Arabic gum, and shellac, along with the presence of PVAc, strengthen the hypothesis that the models suffered alterations and repairs that became necessary with time and use.

\section{Discussion}

Since the glass sheets that compose the models do not show bubbles or any signs of having been blown, relating these observations with the chronology of the models, it is proposed that these were made using float glass. Float glass (also known as window glass) is an industrial process of glass sheets production, where the molten glass is pushed to a molten bath of tin. The glass will then float on the tin and be placed in an annealing kiln until it reaches room temperature. The result is a glass sheet with no bubbles and invisible imperfections to the naked eye. Moreover, the sheets are perfectly plan on both sides, the side that floated on the tin and the other side that is turned to the atmosphere. Relating this with the composition that is proposed, a soda-lime silica type, it is possible to estimate that the glass is not very susceptible to degradation, being a fairly stable composition. Having in mind the glass degradation process, one can for instance compare it with a composition rich in potassium (instead of sodium), which would present a composition much more susceptible to degradation under the same conditions, due to the atomic radius of the potassium ion. Briefly recalling the glass degradation, the first reaction to occur is the ionic exchange, where alkaline ions, negatively charged, are extracted from the glass matrix forming a sodium or potassium hydroxide solution. In order to maintain the matrix neutrality, these leached ions are replaced by $\mathrm{H}_{3} \mathrm{O}^{+}$ions $[19,20]$. $\mathrm{K}$ has an atomic radius bigger than the one of $\mathrm{Na}$, meaning that when the glass has the same composition, changing only the alkali ion (K or Na), for each leached potassium ion, more $\mathrm{H}_{3} \mathrm{O}^{+}$ions will fit into the glass matrix, since K occupied a bigger space than Na [21]. Moreover, the calcium oxide content, which was estimated as above $10 \mathrm{wt} \%$ for all analyzed glasses, acts as a matrix stabilizer (property modifier), contributing to the glass' resistance to degradation [22]. No crystals or iridescent areas were observed on the glass sheets.

Considering now the papers and carboards used on the crystal glass models, they belong to the first full industrial era of paper production, where dangerous materials such as lignin and rosin alum would be expected to be found. In fact, machine made papers from late nineteenth and early twentieth centuries are usually of very poor quality, due mainly to material composition. In the first studies on the deterioration of paper, in Germany, following the creation of the first laboratories for paper testing in 1884, the presence of lignin was classified as one of the main intrinsic causes of the deterioration of the industrial paper. Later, in the 1920's, researchers in Switzerland identified the presence of acidic salts of alum in paper as another of these causes $[23,24]$. These substances act as catalysts for acid hydrolysis, one of the main degradation phenomena of cellulose. The reaction contributes to the breakdown of the polymer chain, affecting the glycosidic bonds that link the glucose units of the cellulose. This results in the formation of acids, which catalyze the hydrolysis, becoming a continuous process of cellulose degradation $[25,26]$. In fact, the phenomenon affects even better quality paper, being intrinsic to the aging and deterioration of cellulose and being dependent on external factors such as environmental conditions and storage [24]. However, the main results reveal the choice of reasonable quality papers for the model's production. This can be proven by the presence of lignin free papers. Even so, the presence of alum salts and rosin sizing, especially in the cardboard models, is a real concern, increasing the risk of deterioration by acid hydrolysis and its collapse over time inside the glass crystal model. 
When thinking about the preventive conservation measures for these objects, a problematic issue stands out: how to create preventive conservation measures that serve both glass and paper? Glass, an inorganic material, needs to be kept in a controlled environment of around $45 \%+/-$ $5 \%$ of relative humidity $(\mathrm{RH})$, and it should never be submitted to extreme $\mathrm{RH}$ fluctuations [27]. The temperature does not represent a big concern, unless it affects the $\mathrm{RH}$, and in relation, light and lighting systems are not a problem, unless these warm up too much. Moreover, the storage and display locations or cabinets should be ventilated to prevent heat and dust accumulation [27]. Concerning the chemical nature of the environment, this should be as neutral as possible. If the environment is an acidic one, the corrosion mechanism will be accelerated and the alkali leaching deepened from the glass matrix. The acid will be a $\mathrm{H}^{+}$source, this way accelerating and deepening the corrosion process. Different acid environments were tested and formic acid, specifically, was determined to be the second factor (after water) to have in mind when dealing with glass conservation $[20,28]$. On the other hand, if the environment is alkaline, especially with a $\mathrm{pH}$ above 9, the silica network dissolution will occur. The silica network dissolution corresponds to the breakdown of siloxane bonds existent on the glass/solution interface [20].

Looking now to paper, in terms of preventive conservation, stable and lower relative humidity are also recommended, but in that case high temperature and light are also important factors of cellulose degradation, accelerating acid hydrolyses but also causing photodegradation and oxidation processes $[29,30]$. As it was seen before, paper degradation can lead to an acidic environment, which can be very dangerous to glass, accelerating its degradation process. Usually, paper also needs and benefits from an alkali reserve, but not higher than $\mathrm{pH} 9$, which also leads to degradation processes, such as alkaline hydrolyses and cellulose peeling-off reaction [29]. As seen above, this would also be dramatic to glass, since atmospheres with $\mathrm{pH}$ above 9 will cause the silica network dissolution. On the other hand, recalling the primary stage of glass degradation, alkali ions will be leached from the glass matrix. So, optimal preventive conservation conditions necessary for glass and paper are compatible, but what are incompatible are the aging degradation processes of each material that develop in opposite ways. However, can the alkali ions freed from the glass be enough to neutralize the acidic species unleashed by aged paper? If so, inside the glass models a favorable microclimate will be created, where the general atmosphere is neutral. The materials will end up reaching an equilibrium point maintaining a neutral environment that suits the conservation of both materials. This is a proposal that needs more research to verify the premise, however, if this ends up being the situation, the conservators need only to monitor the external environment of the models and prevent drastic changes in the temperature and RH so that the internal balance is not disturbed.

Looking to the apparent stability of the models under study, both the inner paper/cardboard of the inner models that although having rosin size, a source of acidity, still maintains its resistance and of glass without visible signs of strong chemical deterioration, this theory seems to make sense and justifies further investigations. In fact, main deterioration processes: (i) Of the glass, concerns physical deterioration from handling and poor storage; (ii) of the paper, concerns a natural yellowing that may have been caused by light-induced degradation and already some acid hydrolysis caused by the presence of rosin in the paper matrix. The water line stains also visible on the paper/cardboard models may be caused by fluctuations of the environmental conditions and formation of water condensation on the glass, which caused these stains on the paper. Other biodegradation and physical deterioration were probably mostly caused by poor handling and poor storage conditions of recent years, where the models had no regular use.

Considering now the labels as part of the historic evidence of the trajectory of these models and recognizing the importance of their safeguarding, the ones possible to identify, such as the Passos Manuel high school and Krantz company, revealed themselves of fair and good quality. However, it is important to be aware that the small labels composed by very poor materials may not last long, unless some remedial conservation is done to neutralize them. It is not known when and why these labels were attached to the glass models, but at least a good record of their existence should be done as 
soon as possible. The same with the so called 'other labels', some of poor quality, that have a number record, which in the future may solve historians' doubts. Fortunately, in that case, acids are not trapped inside the model. So, label composition versus degradation processes of glass are less relevant. But it is always a concern for the general environment and may be for the interface layer between the glass surface and the label, but here there is also the adhesive layers to be considered.

Looking to the results obtained from the analysis performed on the adhesives collected from the exterior tapes that join the glass faces of the crystal models, the majority of the adhesives proved to be of a protein nature. In terms of conservation, protein adhesives can suffer biodeterioration attacks, and depending on the adhesive, these can lose their integrity and adhesive power with age and under certain conditions such as very high or very low $\mathrm{RH} \%$ and temperature. Some of the tapes are already detaching from the glass, which can be a sign that the adhesives are not entirely fulfilling their function. Tapes in general are of good quality, revealing cotton fibers as its main composition. As far as the authors could evaluate, no signs of biodeterioration was identified. However, the need for short period monitoring becomes clear, since the protein adhesives may lose their adhesive power, which will result in the collapse of the entire system of the model. Concerning these materials, there is not much a conservator can do to prevent their falling, apart from a close monitoring and control of the surrounding environment. The identification of materials that, at a first analysis, are believed to be the result of alterations or interventions made on the models to keep them usable, are also important to show the diversity of materials that the conservator has to deal with when thinking about preventive conservation measures for these objects.

\section{Conclusions}

This work aims to be a preliminary approach to the study and characterization of glass crystal models and the materials that are part of their construction. As far as the authors are aware, this is the first systematic and full material study of these types of artefacts that are part of the 20th century legacy of the teaching methods for science and it allows for the understanding of the practices in classes and facilities available in the Portuguese schools, an important subject for the history of science.

The first part of this work was dedicated to the research on the history of these models to understand their origins and creation purposes. This will also be a great contribution to raise the value of this heritage and to open the possibility for other studies concerning these type of artefacts. It was interesting to realize that a large part of the collection, still in a good conservation state, was probably acquired from the Krantz company. The fairly well preserved objects reveal continuous care by the main users of these artefacts. Another interesting aspect was the finding of a probably in-house built model. What was the reason for the creation of this model? Was it a common one or does it reflect the creation of a new type of crystal not yet available in the commercial sector? Were there any financial difficulties faced by the Portuguese education system? So many questions can be asked after this find. However, we are now aware that it must be preserved as a unique piece and that increases its value for the history of science and education. Nevertheless, the materials used to build it are of a poor quality compared with the other models, so it is a conservation challenge to be faced by the conservation team.

The analytical approach proved to be appropriated for the materials' characterization: With pXRF it was possible to determine that the glass is of a soda-lime glass type and the observation under the optical microscope allowed for the identification of the fibers present in the threads from the inner axes and the fibers from the constructive tapes, and for both a mixture of fibers were identified, such as cotton, flax or hemp, and jute. The microchemical tests performed on the cardboard from the interior models revealed the presence of alum salts, alum rosin, and the absence of lignin, which shows a fair-good quality for the paper/cardboard. Finally, ATR-FTIR was used to characterize the adhesives found in the constructive tapes joining the glass sheets. Protein and cellulose were identified as the main adhesives for the majority of analyzed samples. 
The material characterization revealed that the main components that constitute the models are of a reasonably good quality, proving to be stable. However, despite the materials' quality and stability, the main components, glass and paper, have degradation processes that develop in opposite ways. Paper degradation can lead to an acidic environment, which can be very dangerous to glass, accelerating its degradation process. As said before, usually, paper also needs and benefits from an alkali reserve but not higher than $\mathrm{pH} 9$, which also leads to degradation processes. Further research is needed to understand if alkali ions freed from the glass are enough to neutralize the acidic species unleashed by aged paper, which would result in a neutral atmosphere inside the glass models. That way, a favorable microclimate would be created inside the glass models, being of paramount importance to keep the external environment stable not to disturb the internal equilibrium. As already mentioned, further research is needed to understand the implications of the combination of the degradation processes of these two materials.

This first approach to the study of these models will serve as a base of knowledge for the development of preventive conservation measurements for these types of models and the identification of the main conservation issues concerning this cultural heritage. As future work, guidelines will be developed for schools, museums, and other institutions that will help these establishments in the preservation of their collections.

Author Contributions: Conceptualization, I.C. and C.C.; methodology, I.C., C.C. and J.L.F.; software, I.C., C.C., J.L.F. and C.P.; validation, I.C., C.C. and J.L.F.; formal analysis, I.C., C.C., J.L.F. and C.P.; investigation, I.C., C.C., J.L.F. and C.P.; resources, I.C., C.C., J.L.F. and C.P.; data curation, I.C., C.C., J.L.F. and C.P.; writing-original draft preparation, I.C.; writing-review and editing, I.C., C.C. and J.L.F.; visualization, I.C., C.C., J.L.F. and C.P.; supervision, I.C. and C.C.; project administration, I.C. and C.C.; funding acquisition, I.C. and C.C.

Funding: This work has been partially funded by the Fundação do Ministério de Ciência e Tecnologia de Portugal through the research unit VICARTE (Project ref. UID/EAT/00729/2013). This work was supported by the Associate Laboratory for Green Chemistry-LAQV which is financed by national funds from FCT/MCTES (UID/QUI/50006/2019).

Acknowledgments: The authors would like to thank to Catarina Mateus, Laura Moura, Manuela Mineiro and Marta Lourenço (MUHNAC, University of Lisbon), Maria Ribeiro and Helena Simões (Passos Manuel Secundary School). This paper benefited from the use of the Portuguese Infrastructure of Scientific Collections (PRISC.pt) (POCI-01-0145FEDER-022168).

Conflicts of Interest: The authors declare no conflict of interest.

\section{References}

1. Gomes, I. Os Museus Escolares de História Natural-Análise Histórica e Perspectivas de Futuro (1836-1975). Ph.D. Thesis, History and Philosophy of Sciences, Faculdade de Ciências da Universidade de Lisboa, Lisboa, Portugal, 2014.

2. Schuh, C.P. Geometrical Crystallography. In Mineralogy E Crystallography: On the History of These Sciences from Beginnings Through 1919; AZ_Draft Edition; Curtis Schuh: Tucson, AZ, USA, 2007; pp. 197-201.

3. Agricola, G. De Natura Fossilium; Marix Verlag: Wiesbaden, Germany, 2013.

4. Medium. Available online: https://medium.com/designscience/crystal-models5fed8679289f (accessed on 17 July 2019).

5. Plan for the Portuguese High Schools, approved by Legislative Decree, 17th November 1836, published at Diário do Governo no. 275. 19 November 1836.

6. KRANTZ. Ältestes Geologisches Warenhaus Weltweit. Available online: https://www.krantz-online.de/en/ about_us/history.html (accessed on 19 July 2019).

7. Mineralogy. Available online: http://www.mineralogy.eu/archive/Krantz/catalogs.html (accessed on 17 July 2019).

8. Marshall, J.A. The Identification of Flax, Hemp, Jute and Ramie in Textil Artifacts. Master's Thesis, University of Alberta, Edmonton, AB, Canada, 1992.

9. American Institute for Conservation. Paper Conservation Catalog, Fiber Identification. Mayer, D., Ed.; 2013. Available online: https://www.conservation-wiki.com/wiki/BP_Chapter_1_-_Fiber_Identification (accessed on 20 July 2019). 
10. Ilvessalo-Pfäffli, M.-S. Fiber Atlas. Identification of Papermaking Fibers; Timell, T.E., Ed.; Springer: Berlin/Heidelberg, Germany, 1995; p. 399.

11. American Institute for Conservation. Paper Conservation Catalog. Mayer, D., Ed.; 2013. Available online: http://cool.conservation-us.org/coolaic/sg/bpg/pcc/10_spot-tests.pdf (accessed on 20 June 2019).

12. Barrow, W.J. Spot Testing for the Unstable Modern Book and Record Papers. Permanence/Durability of the Book-VI; W.J. Barrow Research Laboratory: Richmond, VA, USA, 1969.

13. Carroll, S.; Nancy, O.; Werber, S. Material characterization tests for objects of art and archaeology, 2nd ed.; Archetype Publications: London, UK, 2005.

14. Brill, R. Chemical Analyses of Early Glasses; The Corning Museum of Glass: Corning, NY, USA, 1999; Volume II, p. 544.

15. Coutinho, I. New Insights into 17th and 18th Century Glass from Portugal: Study and Preservation. Ph.D. Thesis on Conservation and Restoration, NOVA University of Lisbon, Lisbon, Portugal, 13 July 2016.

16. Navarro, J. Removing Paper Labels from Ceramics and Glass. Conservator 1997, 21, 21-26. [CrossRef]

17. Derrick, M.R.; Stulik, D.; Landry, J.M. Spestral Interpretation. In Infrared Spectroscopy in Conservation Science, 1st ed.; The Getty Conservation Institute: Los Angeles, CA, USA, 2000; p. 108.

18. Hospodarova, V.; Singovszka, E.; Stevulova, N. Characterization of cellulosic fibers by FTIR spectroscopy for their further implementation to building materials. Am. J. Anal. Chem. 2018, 9, 303-310. [CrossRef]

19. Davison, S. Conservation and Restoration of Glass, 2nd ed.; Butterworth-Heinemann: Oxford, UK, 2003.

20. Robinet, L.; Hall, C.; Eremin, K.; Fearn, S.; Tate, J. Alteration of soda silicate glasses by organic pollutants in museums: Mechanisms and kinetics. J. Non-Cryst. Solid 2009, 355, 1479-1488. [CrossRef]

21. Clark, D.E.; Pantano, C.G.; Hench, L.L. Corrosion of Glass. Surf. Sci. 1979, 100, 1-6, $22-28$.

22. Shelby, J.E. Introduction to Glass Science and Technology, 2nd ed.; The Royal Society of Chemistry: Cambridge, UK, 2005; pp. 26-30.

23. Burns, T. 'A Serious and Universal Evil': The Early Scientific Study of Paper Deterioration. In Works of Art on Paper: Books, Documents and Photographs; Techniques and Conservation, Proceedings of the Baltimore Congress, London, England, 2-6 September 2009; Daniels, V., Donnithorne, A., Smith, P., Eds.; IIC: London, UK, 2002; pp. 36-41.

24. Casanova, C. De artífice a Cientista. Ph.D. Thesis, Conservation Restoration, Faculdade de Ciências e Tecnologia, Universidade Nova de Lisboa, Lisboa, Portugal, 2012.

25. Sharples, A. Acid Hydrolysis and Alcoholysis. In Cellulose and Cellulose Derivates, 2nd ed.; Bikales, N.M., Segal, L., Eds.; Wiley Interscience: New York, NY, USA, 1971; pp. 991-1006.

26. Whitmore, P.; Bogaard, J. Determination of the Cellulose Scission Route in the Hydrolytic and Oxidative Degradation of Paper. Restaurator 1994, 15, 26-45. [CrossRef]

27. Koob, S. Conservation and Care of Glass Objects; Archetype Publications: New York, NY, USA, 2006; pp. 131-150.

28. Robinet, L.; Eremin, K.; Coupry, C.; Hall, C.; Lacome, N. Effect of Organic Acid Vapors on the Alteration of Soda Silicate Glass. J. Non-Cryst. Solid 2007, 353, 1546-1559. [CrossRef]

29. Strlic, M.; Kolar, J. Ageing and Stabilization of Paper; National and University Library: Ljubljana, Slovenia, 2005; p. 205.

30. Vailant Callol, M.; Rodrigo, N. Principios Básicos de La Conservation Documental y Causas de su Deterioro; Secretaría General Técnica-Centro de Publicaciones: Madrid, Spain, 1996.

(C) 2019 by the authors. Licensee MDPI, Basel, Switzerland. This article is an open access article distributed under the terms and conditions of the Creative Commons Attribution (CC BY) license (http://creativecommons.org/licenses/by/4.0/). 